\title{
Relating crystal structure to vapochromic responses in polymorphic compounds
}

\author{
Nathaniel Barker ${ }^{a}$, Stephen Taylor ${ }^{b}$, Ethan Ferguson ${ }^{c}$, Jeanette Krause ${ }^{d}$, William \\ Connick $^{\mathrm{e}}$, and Peng Zhang ${ }^{\mathrm{f}}$ \\ aUniversity of Cincinnati Department of Chemistry, Cincinnati, Ohio 45221, USA, \\ barkernl@mail.uc.edu \\ b University of Cincinnati Department of Chemistry, Cincinnati, Ohio 45221, USA, \\ taylo264@gmail.com \\ c University of Cincinnati Department of Chemistry, Cincinnati, Ohio 45221, USA, \\ ethanf109@gmail.com \\ d University of Cincinnati Department of Chemistry, Cincinnati, Ohio 45221, USA, \\ krauseje@ucmail.uc.edu \\ 'Recently Deceased. \\ f University of Cincinnati Department of Chemistry, Cincinnati, Ohio 45221, USA, \\ zhangph@ucmail.uc.edu
}

Vapochromic compounds have been well-known for many years. However, not until the work of

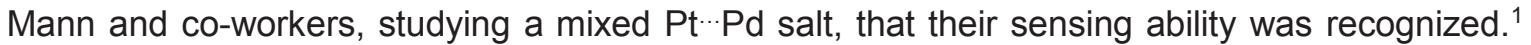
Since then, vapochromic materials, specifically Pt-centered vapochromic complexes, have been widely studied. ${ }^{2-4}$

We have been working with a vapochromic Pt salt that forms different polymorphs dependent on the recrystallization technique. Upon isolation, these types of materials can be used to detect different volatile organic compounds (VOC's) or environmentally-troublesome anions with high selectivity and sensitivity by undergoing a noticeable color change. In addition, the emission and response properties undergo a shift that can be directly related to the intra- and inter-dimer Pt $\cdots \mathrm{Pt}$ distances of the respective polymorph. X-ray crystallography has been vital in determining the overall structures of these polymorphic complexes and the details of the Pt. Pt interactions that give rise to the color, luminescence, and response properties of these materials.

\section{References}

[1] Exstrom, C. L. et al. (1995). Chem. Mater. 7, 15-17.

[2] Wenger, O. S. (2013). Chem. Rev. 113, 3686-3733.

[3] Grove, L. J. et al. (2004). J. Am. Chem. Soc. 126, 1594-1595.

[4] Kumpfer, J. R. et al. (2012). J. Mater. Chem. 22, 14196-14204. 